\title{
Evolutionary Relationships among Eubacterial Groups as Inferred from GroEL (Chaperonin) Sequence Comparisons
}

\author{
ALEJANDRO M. VIALE, * ADRIÁN K. ARAKAKI, FERNANDO C. SONCINI, AND RAÚL G. FERREYRA \\ Departmento de Microbiología, Facultad de Ciencias Bioquímicas y Farmacéuticas, Universidad Nacional de Rosario, \\ 2000 Rosario, Argentina
}

\begin{abstract}
The essential GroEL proteins represent a subset of molecular chaperones ubiquitously distributed among species of the eubacterial lineage, as well as in eukaryote organelles. We employed these highly conserved proteins to infer eubacterial phylogenies. GroEL from the species analyzed clustered in distinct groups in evolutionary trees drawn by either the distance or the parsimony method, which were in general agreement with those found by $16 \mathrm{~S}$ rRNA comparisons (i.e., proteobacteria, chlamydiae, bacteroids, spirochetes, firmicutes [gram-positive bacteria], and cyanobacteria-chloroplasts). Moreover, the analysis indicated specific relationships between some of the aforementioned groups which appeared not to be clearly defined or controversial in rRNA-based phylogenetic studies. For instance, a monophyletic origin for the low-G+C and high-G+C subgroups among the firmicutes, as well as their specific relationship to the cyanobacteria-chloroplasts, was inferred. The general observations suggest that GroEL proteins provide valuable evolutionary tools for defining evolutionary relationships among the eubacterial lineage of life.
\end{abstract}

The study of macromolecules emphasizing the historical information contained in their sequences has resulted in profound changes in our conception of the evolution of life on our planet, with its attendant consequences for the classification of living organisms $(27,30,43,53)$. In particular, comparisons of the 16S rRNA sequences from a large number of species have been pivotal in providing evidence of three primary lines of descent, two of them leading to the prokaryotic lineages (Eu) Bacteria and Archaea $(27,28,30,53)$. These studies also indicate that the eubacterial lineage has evolved into (at least) 10 distinct divisions, although the specific relationships among (and sometimes within) them have yet to be convincingly determined $(28,30,31,43,53,56)$.

Given the limitations inherent in the assumptions on which current phylogenetic methods are based, phylogenies based on a single macromolecule may not necessarily reflect the true phylogeny of the lineages in which it occurs $(5,9,15,30,43,44$, 56). Therefore, it is becoming increasingly evident that resolution of the evolutionary relationships between organisms (especially prokaryotes) undoubtedly requires comparative analysis of data from different macromolecules showing useful features as molecular chronometers $(5,30,43)$.

The GroEL, or Hsp60 (the common major antigen in numerous eubacterial genera [7]), chaperonins constitute a family of highly conserved housekeeping proteins. These proteins are ubiquitously distributed among eubacteria and eukaryotic organelles and possess functions essential for the survival of cells in physiological, as well as stressful, situations $(7,10,13)$. The similarities between evolutionary trees drawn from a limited set of these molecules and those of 16S rRNA have been noted previously $(7,10)$. We extended this phylogenetic analysis by using an expanded GroEL data base and found that these proteins represent valuable molecular chronometers.

* Corresponding author. Phone: (54-41) 821701. Fax: 54-41-300309 or 54-41-240010. Electronic mail address: rnviale@arcride.edu.ar.

\section{MATERIALS AND METHODS}

GroEL as an evolutionary chronometer. Widely different base compositions in the different lineages under study have been reported to constitute potential sources of inconsistencies when nucleotide sequences (including those of rRNA) are compared for phylogenetic studies $(15,30,44)$. Since this substitutional bias is minimized in highly conserved proteins $(15,20)$, inferences based on comparisons of their amino acid sequences have been proposed to be more reliable than those based on the corresponding nucleotide sequences (15).

Analysis of the GroEL proteins of the organisms listed in Table 1 indicates that the tendencies seen in nonconserved proteins (i.e., correlation of low $\mathrm{G}+\mathrm{C}$ base content with increases in Ile, Lys, Phe, and Tyr on the one hand and high $\mathrm{G}+\mathrm{C}$ content with Ala, Arg, and Gly on the other [20]) are minimized in these highly conserved proteins (49) and that most of the amino acid changes result in conservative substitutions $(10,49)$. Moreover, the size (ca. 550 amino acid residues), as well as the highly conserved function, of these proteins $(10,13)$ appears to include most of the desirable features of a molecular chronometer $(30,43,53)$. Therefore, we used comparisons of GroEL amino acid sequences rather than the corresponding nucleotide sequences for inferences of eubacterial phylogenies.

Data sources and data base searches. The organisms from which groEL genes have been characterized, their affiliations according to 16S rRNA analysis, and the sources of information are provided in Table 1 . DNA and protein data base searches were performed at the National Center for Biotechnology Information by using the BLAST network service (2).

Data analysis. Alignments of the $58 \mathrm{GroEL}$ protein sequences indicated in Table 1 were done as described previously (10), and final adjustments were decided after visual inspection. To calculate evolutionary distances, 525 aligned positions were employed after removal of ambiguous alignments that include in all sequences a stretch of nine amino acids equivalent to Escherichia coli GroEL positions 427 to 435), the C-terminal portion (starting at the position equivalent to $E$. coli GroEL position 531), and transit peptides from eukaryotic sequences. Evolutionary distances were computed by using the amino acid conversion table (PAM 001) compiled by Dayhoff 
TABLE 1. Organisms, corresponding affiliations, and sources of Hsp60 sequences used in this work

\begin{tabular}{|c|c|c|}
\hline Organism and affiliation $^{a}$ & $\begin{array}{l}\text { GenBank } \\
\text { accession no. }\end{array}$ & Reference \\
\hline $\begin{array}{l}\alpha \text {-Proteobacteria } \\
\text { Bartonella bacilliformis } \\
\text { Brucella abortus } \\
\text { Agrobacterium tumefaciens } \\
\text { Rhizobium leguminosarum } \\
\text { Rhizobium meliloti } \mathrm{A}^{c} \\
\text { Rhizobium meliloti } \mathrm{C} \\
\text { Rhizobium meliloti } \mathrm{C}^{c} \\
\text { Bradyrhizobium japonicum } 2^{c} \\
\text { Bradyrhizobium japonicum } 3^{c} \\
\text { Zymomonas mobilis } \\
\text { Ehrlichia chaffeensis } \\
\text { Rickettsia tsutsugamushi }\end{array}$ & $\begin{array}{l}\text { M98257 } \\
\text { L09273 } \\
\text { X68263 } \\
\text { L20775 } \\
\text { M94192 } \\
\text { M94190 } \\
\text { M94191 } \\
\text { Z22604 } \\
\text { Z22603 } \\
\text { L11654 } \\
\text { L10917 } \\
\text { M31887 }\end{array}$ & $\begin{array}{l}\mathrm{UD}^{h} \\
14 \\
39 \\
\mathrm{UD} \\
35 \\
35 \\
35 \\
11 \\
11 \\
\mathrm{UD} \\
46 \\
45\end{array}$ \\
\hline $\begin{array}{l}\text { ß-Proteobacteria } \\
\text { Neisseria gonorrhoeae } \\
\text { Neisseria flavescens } \\
\text { Neisseria meningitidis }\end{array}$ & $\begin{array}{l}\text { Z23008 } \\
\text { Z22955 } \\
\text { Z22956 }\end{array}$ & $\begin{array}{l}\text { UD } \\
\text { UD } \\
\text { UD }\end{array}$ \\
\hline $\begin{array}{l}\gamma \text {-Proteobacteria } \\
\text { Coxiella burnetii } \\
\text { Pseudomonas aeruginosa } \\
\text { Haemophilus ducreyi } \\
\text { Salmonella typhi } \\
\text { Escherichia coli } \\
\text { Symbiont P of Acyrthosiphon pisum } \\
\text { Yersinia enterocolitica } \\
\text { Chromatium vinosum } \\
\text { Legionella pneumophila } \\
\text { Legionella micdadei } \\
\text { Symbiont of } \text { Amoeba proteus }\end{array}$ & $\begin{array}{l}\text { M20482 } \\
\text { M63957 } \\
\text { M91030 } \\
\text { U01039 } \\
\text { X07850 } \\
\text { X61150 } \\
\text { X68526 } \\
\text { M99443 } \\
\text { M31918 } \\
\text { X57520 } \\
\text { M86549 }\end{array}$ & $\begin{array}{l}10 \\
42 \\
32 \\
\text { UD } \\
16 \\
10 \\
\text { UD } \\
10 \\
18 \\
10 \\
1\end{array}$ \\
\hline $\begin{array}{l}\delta / \varepsilon-\text { Proteobacteria } \\
\text { Helicobacter pylori }\end{array}$ & X73840 & 23 \\
\hline $\begin{array}{l}\text { Bacteroids } \\
\quad \text { Porphyromonas gingivalis }\end{array}$ & D17398 & UD \\
\hline $\begin{array}{l}\text { Chlamydiae } \\
\text { Chlamydia trachomatis } \\
\text { Chlamydia pneumoniae } \\
\text { Chlamydia psittaci }\end{array}$ & $\begin{array}{l}\text { M31739 } \\
\text { M69217 } \\
\text { X51404 }\end{array}$ & $\begin{array}{l}10 \\
21 \\
10\end{array}$ \\
\hline $\begin{array}{l}\text { Spirochetes } \\
\text { Leptospira interrogans } \\
\text { Borrelia burgdorferi } \\
\text { Treponema pallidum }\end{array}$ & $\begin{array}{l}\text { L14682 } \\
\text { X54059 } \\
\text { X54111 }\end{array}$ & $\begin{array}{l}3 \\
40 \\
17\end{array}$ \\
\hline $\begin{array}{l}\text { Firmicutes (gram-positive bacteria), } \\
\text { low G+C content } \\
\text { Clostridium perfringens } \\
\text { Clostridium acetobutylicum } \\
\text { Thermophilic bacterium PS-3 } \\
\text { Bacillus stearothermophilus } \\
\text { Bacillus subtilis } \\
\text { Lactococcus lactis } \\
\text { Staphylococcus aureus }\end{array}$ & $\begin{array}{l}\text { X62914 } \\
\text { M74572 } \\
\text { P26209 } \\
\text { L10132 } \\
\text { M81132 } \\
\text { X71132 } \\
\text { S62126 }\end{array}$ & $\begin{array}{l}10 \\
10 \\
10 \\
38 \\
10 \\
\text { UD } \\
29\end{array}$ \\
\hline $\begin{array}{l}\text { Firmicutes (gram-positive bacteria), } \\
\text { high G+C content } \\
\text { Streptomyces albus } \\
\text { Mycobacterium leprae } \\
\text { Mycobacterium tuberculosis } \\
\text { Mycobacterium paratuberculosis } \\
\text { Streptomyces albus }{ }^{c} \\
\text { Streptomyces coelicolor } \\
\text { Mycobacterium leprae } \\
\text { Mycobacterium tuberculosis }\end{array}$ & $\begin{array}{l}\text { M76658 } \\
\text { M14341 } \\
\text { M17705 } \\
\text { X74518 } \\
\text { M76657 } \\
\text { X75206 } \\
\text { S25181 } \\
\text { X60350 }\end{array}$ & $\begin{array}{l}25 \\
26 \\
41 \\
\text { UD } \\
25 \\
\text { UD } \\
34 \\
\text { UD }\end{array}$ \\
\hline
\end{tabular}

TABLE 1. Continued

\begin{tabular}{|c|c|c|}
\hline Organism and affiliation ${ }^{a}$ & $\begin{array}{c}\text { GenBank } \\
\text { accession no. }\end{array}$ & Reference \\
\hline \multicolumn{3}{|l|}{ Cyanobacteria } \\
\hline Synechococcus sp. strain PCC 7942 & M58751 & 10 \\
\hline Synechocystis sp. strain PCC $6803^{c}$ & D12677 & 10 \\
\hline Synechocystis sp. strain PCC 6803 & M57517 & 22 \\
\hline \multicolumn{3}{|l|}{ Chloroplasts } \\
\hline Cyanidium caldarium & X62578 & 24 \\
\hline Triticum aestivum $\alpha^{d}$ & $\mathrm{X} 07851$ & 16 \\
\hline Ricinus communis $\alpha$ & X07852 & 16 \\
\hline Brassica napus $\alpha$ & M35599 & 10 \\
\hline Brassica napus $\beta^{d}$ & M35600 & 10 \\
\hline Arabidopsis thaliana $\beta$ & $\mathrm{JT} 0901^{e}$ & 55 \\
\hline \multicolumn{3}{|c|}{$\begin{array}{l}{ }^{a} \text { As indicated by } 16 \mathrm{~S} \text { rRNA analysis }(28,31) . \\
{ }^{b} \mathrm{UD} \text {, unpublished data. } \\
{ }^{c} \text { groEL is present in a groESL operon (this applies only in cases in which more } \\
\text { than one groEL gene has been reported in a particular species). } \\
{ }^{d} \alpha / \beta \text { indicates the type of polypeptide that composes the plant chloroplast }\end{array}$} \\
\hline & GroEL chaperonin $(10)$ & \\
\hline
\end{tabular}

et al. (8). For construction of phylogenetic trees, we employed the neighbor-joining distance method (36), which has been shown in model studies to be relatively consistent compared to other methods, even in the presence of unequal rates of evolution (36). For comparisons, phylogenetic trees were also inferred by using the PROTPARS maximum-parsimony method (9). Confidence limits for the inferences obtained were placed by using the "bootstrap" procedure (9).

The programs PROTDIST, NEIGHBOR, PROTPARS, SEQBOOT, and CONSENSE, present in the PHYLIP package (9), version 3.5 (kindly provided by J. Felsenstein, University of Washington, Seattle), were employed in this work. GroEL protein alignments and evolutionary distances were provided for the reviewing process and are available from us on request.

\section{RESULTS AND DISCUSSION}

The evolutionary relationships between the eubacterial species listed in Table 1, as inferred from their GroEL proteins, are shown in Fig. 1. Our analyses by the distance (Fig. 1) and parsimony (data not shown) methods indicate the presence of two defined clusters, one of which includes proteobacteria, chlamydiae, spirochetes, and the eubacterial species Porphyromonas gingivalis and Helicobacter pylori and appears to be clearly separated from another cluster formed by cyanobacteria-chloroplasts and firmicutes. Detailed comparison of the amino acid sequences indicated that the homologs from the former cluster (i.e., proteobacteria, chlamydiae, spirochetes, $P$. gingivalis, and $H$. pylori) contain a Lys residue at the position equivalent to $E$. coli GroEL position 51, whereas an Asn residue is present at the equivalent position in those from the cyanobacteria-chloroplasts-firmicutes cluster (49).

We have analyzed the results shown in this work at two levels, both within and between each of the distinct groups depicted in Fig. 1, contrasting our observations with the evolutionary relationships based on 16S rRNA analysis $(4,6$, $28,30,31,33,37,43,48,51-54,56)$ as follows.

Proteobacteria. This eubacterial division contains a large number of species whose outstanding attribute is their diversity of phenotypes (56). The proteobacteria (as a whole) could not be defined by a simple signature in $16 \mathrm{~S}$ rRNA comparisons; 
only phylogenetic trees based on this molecule define this group $(43,53,56)$. Since some degree of uncertainty has been found in these inferences, their corroboration by the use of other molecules is important from an evolutionary perspective (43). Our analysis based on GroEL sequence comparisons tends to support rRNA-based inferences, including the separation of proteobacterial species into distinct subdivisions depicted in rRNA trees, as well as the internal relationships found in these analyses within them $(4,6,28,30,31,33,37,43$, $48,51-54,56)$, as discussed below.

$\boldsymbol{\alpha}$-Proteobacteria. We observed that the species assigned to the $\alpha$-proteobacterial subdivision by rRNA analysis $(4,6,28$, $31,37,43,51-54,56)$ also clustered in GroEL-derived trees drawn by either the distance (Fig. 1) or the parsimony (data not shown) method. Our analysis revealed a clearly defined subgroup within the $\alpha$-proteobacteria which includes two species of rhizobia, as well as Agrobacterium tumefaciens, Brucella abortus, Bartonella bacilliformis, Bradyrhizobium japonicum, and Zymomonas mobilis (Fig. 1). This group has also been observed in rRNA trees and designated the Agrobacterium-Rhizobium cluster (51). Interestingly, we observed within this cluster a closer relationship between the GroEL proteins of $B$. bacilliformis, $B$. abortus, Rhizobium leguminosarum, and A. tumefaciens and the protein encoded by groESL operon A of R. meliloti (35) (Fig. 1). This particular affiliation was also supported by a peculiarity in the protein sequences which occurs only among the latter five species at the position equivalent to $E$. coli GroEL position 427 (a Thr [or Ser] residue followed immediately by an amino acid deletion [49]). It is worth mentioning that similar affiliations (i.e., a closer relationship between Agrobacterium, Rhizobium, Brucella, and Bartonella species and the presence of Bradyrhizobium species as loosely related to the bacteria mentioned among the $\alpha$-proteobacteria) have been determined by $16 \mathrm{~S}$ rRNA analysis (4, $37,51,52,54)$.

Phylogenetic trees derived by both distance (Fig. 1) and parsimony (data not shown) analyses of GroEL suggest that the aforementioned Agrobacterium-Rhizobium cluster is distant from but specifically related to a fast-evolving subgroup that includes Ehrlichia chaffeensis and Rickettsia tsutsugamushi (family Rickettsiaceae [51]). Although the unique phenotypic traits of $R$. tsutsugamush $i$ have made its classification uncertain $(7,45)$, recent $16 \mathrm{~S}$ rRNA analysis has indicated that this organism is closely affiliated with species of the genus Rickettsia (6), which in turn form a cluster with those of the genus Ehrlichia $(4,6,31)$, in agreement with our observations (Fig. 1 ). The latter results are particularly relevant to the observation that mitochondrial GroEL homologs are closely affiliated with those of the aforementioned Rickettsia-Ehrlichia cluster (50), which not only supports the proposed $\alpha$-proteobacterial ancestry for the mitochondrion (5) but also focuses on the nature of its putative closest ancestors, as discussed elsewhere (50).

The situation of $R$. meliloti and $B$. japonicum merits comment, given that several groEL genes have been identified in these bacteria $(11,35)$. Our results (Fig. 1) suggest that the $B$. japonicum groEL genes likely represent products of a duplication event. On the other hand, two of the $R$. meliloti GroEL proteins (those encoded by gene C and groESL operon C [35]) were found in our analysis not immediately affiliated to their homolog present in operon A but related to those of $B$. japonicum (although bootstrap analysis did not provide high confidence for this particular affiliation; Fig. 1). Given that only the product of groESL operon A shows the sequence idiosyncrasy mentioned above, as well as the close similarity between these particular affiliations and those obtained for the same species by $16 \mathrm{~S}$ rRNA analysis $(4,37,52,54)$, it seems reasonable to propose that the aboriginal $R$. meliloti groESL genes are represented by operon $\mathrm{A}$. The two extra gro $E$ genes (gene $\mathrm{C}$ and that of operon $\mathrm{C}$ [35]) may have been acquired by lateral gene transfer, a situation not totally unexpected among soil bacteria. Nevertheless, alternative explanations for these results would be based on assuming either the loss of some duplicated genes in all of the proteobacterial species examined (with the exception of $B$. japonicum and $R$. meliloti) or differential evolution of $R$. meliloti groEL genes after duplication.

$\beta$ - and $\gamma$-Proteobacteria. GroEL from species of the $\beta$ - and $\gamma$-proteobacterial subgroups (as defined by $16 \mathrm{~S}$ rRNA analysis) clearly clustered in our analysis (Fig. 1), and the phylogenetic tree obtained closely resembles those obtained by $16 \mathrm{~S}$ rRNA analyses $(28,31,43,48,53,56)$. For instance, a clearly defined cluster formed by Haemophilus ducreyi, Yersinia enterocolitica, E. coli, Salmonella typhi, and symbiont $\mathrm{P}$ of Acyrthosiphon pisum was observed (Fig. 1), therefore reinforcing the specific relationships between these bacterial species found in $16 \mathrm{~S}$ rRNA trees $(28,31)$, as well as the affiliation of the latter symbiont with the $Y$. enterocolitica-enteric bacteria cluster among the $\gamma$-proteobacteria (48). On the other hand, the endosymbiont of Amoeba proteus (X-bacterium [1]) was found in close affiliation with a distinct cluster within the $\gamma$-proteobacteria formed by Legionella species (Fig. 1). This represents the first classification of the latter bacterium based on a comparison of molecular sequences.

The specific affiliations of Chromatium vinosum, Coxiella burnetii, and Pseudomonas aeruginosa within the $\gamma$-proteobacteria could not be defined precisely in our study, as judged by the bootstrap values obtained in these cases (Fig. 1). In any case, the presence of the phototroph $C$. vinosum in this proteobacterial subdivision reinforces the idea that all of these species evolved from free-living, phototrophic ancestors $(10$, 53). In turn, the presence of $C$. burnetii within the $\gamma$-proteobacteria, in addition to the aforementioned affiliation of $B$. bacilliformis with $\alpha$-proteobacterial species (Fig. 1), supports the proposed polyphyletic nature of the order Rickettsiales, as well as the family Rickettsiaceae $(4,51)$.

Interestingly, although GroEL sequences from only a single $\beta$-proteobacterial genus (i.e., Neisseriq) were available for analysis, our results (Fig. 1) are in line with the presence in rRNA trees of the $\beta$-proteobacteria as a subgroup (albeit deeply branching $[43,53])$ of the $\gamma$-proteobacteria.

Chlamydiae. The chlamydiae constitute a group of obligate intracellular organisms that are differentiated from other bacteria by their unique developmental cycles (53). In GroELbased phylogenetic trees drawn by either the distance (Fig. 1) or the parasimony (data not shown) method, $C$. trachomatis, $C$. psittaci, and $C$. pneumoniae formed a clearly defined cluster, an observation that sustains results based on rRNA analyses (12, $28,30,31,43,53,56)$. Moreover, our results also reinforce the closer affiliation of C. pneumoniae with C. psittaci (12), despite the low degree of homology between these organisms on the DNA level.

Spirochetes. GroEL chaperonins from the spirochetal species analyzed (Leptospira interrogans, Treponema pallidum, and Borrelia burgdorferi) formed a cluster separate from those of the other eubacterial groups by either the distance (Fig. 1) or the parsimony (data not shown) method, a result that reinforces the conclusions drawn from comparisons of their phenotypes, as well as rRNA analysis $(28,30,31,43,53,56)$, including the early branching of the leptospires in these trees (31).

$\boldsymbol{H}$. pylori and $\boldsymbol{P}$. gingivalis. $H$. pylori and $P$. gingivalis have been assigned by rRNA analysis to the $\delta / \varepsilon$-proteobacteria $(H$. 


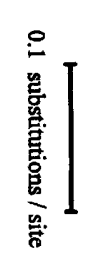

Proteobacteria

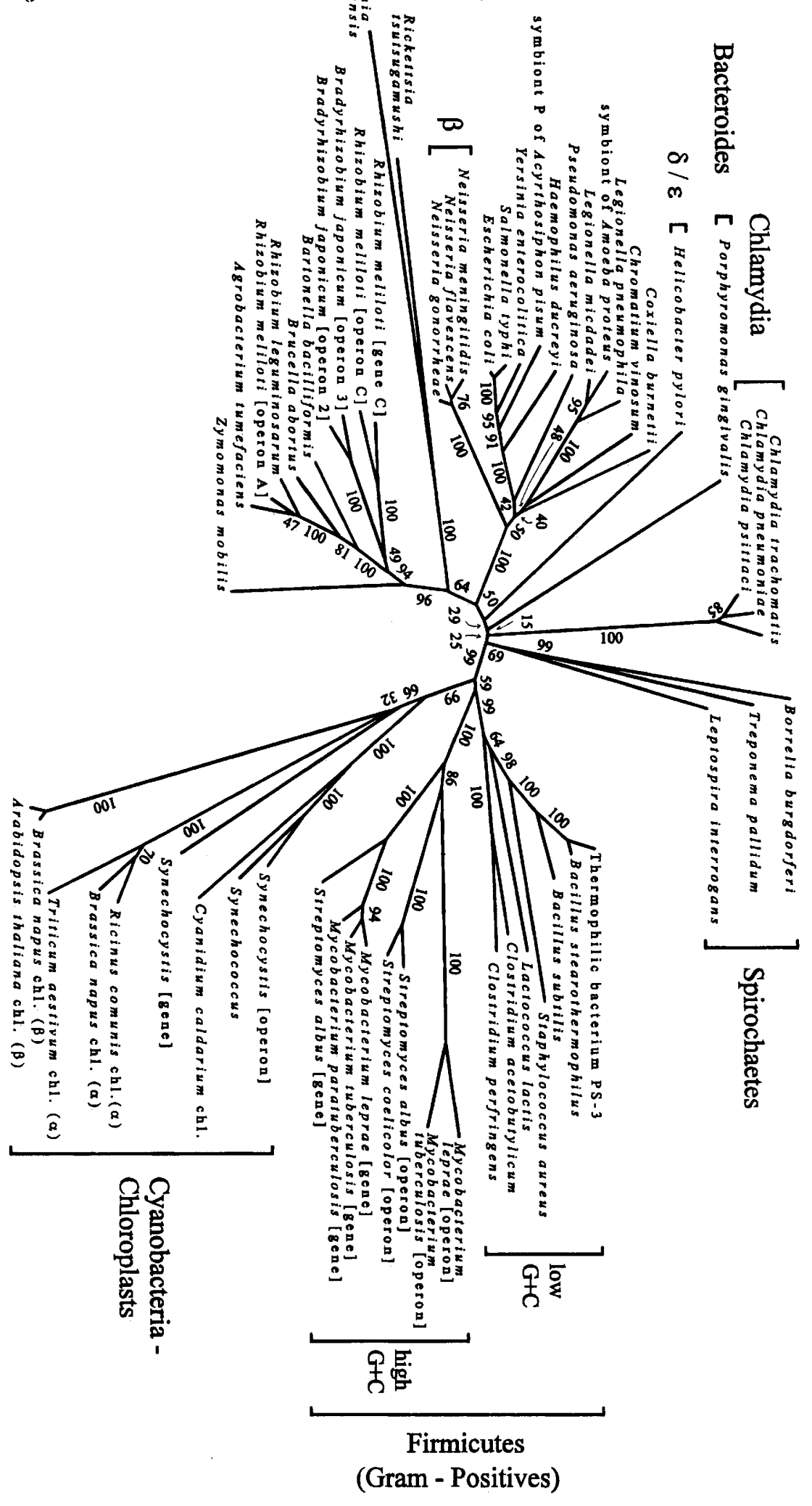


FIG. 1. Evolutionary relationships between eubacterial species and groups based in GroEL sequence comparisons. An unrooted phylogenetic tree was constructed by the neighbor-joining distance method (36) as described in Materials and Methods. The number at end branch indicates the number of times that the adjacent two groups it defines occurred, as obtained by the bootstrap procedure from 100 replicated trees (9). The designations [operon] and [gene] indicate the presence of more than one groEL gene in a particular species, either linked to a groES gene in a groESL operon ([operon]) or in a form ([gene]) which is not immediately linked to groES. The length of each branch is proportional to the calculated evolutionary distance, and the scale is indicated at the bottom. The denomination of the major eubacterial groups is that of Table 1 .

pylori $[28,31])$ and to the bacteroids among the CytophagaFlavobacter-Bacteroides group ( $P$. gingivalis [33]). Although in these cases the number of GroEL sequences is quite restricted and bootstrap analysis did not provide enough confidence for these particular affiliations to allow definite conclusions, it is worth mentioning that the branching orders in Fig. 1 corresponding to proteobacteria, chlamydiae, spirochetes, and $P$. gingivalis were reproducibly formed and resemble those observed for the corresponding groups in recently published $16 \mathrm{~S}$ rRNA trees $(28,31)$.

In any case, a larger groEL data base, especially from $\delta / \varepsilon$-proteobacterial species, as well as from the bacteroids and related groups $(28,31)$, may be necessary to clarify these particular affiliations.

Cyanobacteria-chloroplasts. GroEL from Synechococcus and Synechocystis species, as well as those from several plastids, formed a clearly defined cluster in either distance or parsimony analysis (Fig. 1 and data not shown). This result agrees with inferences based on rRNA comparisons concerning the putative affiliation of the symbiont that generated the chloroplasts among all of the photosynthetic eukaryotes (including red algae) in the cyanobacterial lineage $(5,50,53)$. A detailed discussion of these results has been published elsewhere (50).

Firmicutes. The species of the firmicutes group have been referred to as gram-positive bacteria $(28,30,43,53,56)$ or posibacteria (5). In turn, in the 1984 edition of Bergey's Manual of Systematic Bacteriology, these organisms are classified as firmicutes, a term that is indicative of the rigid, dense cell walls of most of the species that form this eubacterial division (27) and which we have used in this work.

Either distance (Fig. 1) or parsimony (data not shown) analysis clearly separated the species of firmicutes with high $\mathrm{G}+\mathrm{C}$ content from those with low $\mathrm{G}+\mathrm{C}$ content. The bacterial relationships within the low- $\mathrm{G}+\mathrm{C}$ content subgroup closely resembled those of rRNA trees $(28,31,43)$, e.g., the clustering of clostridial species and their separation from the group formed by Lactococcus lactis, Staphylococcus aureus, Bacillus subtilis, and B. stearothermophilus (Fig. 1). It is also worth noting the specific affiliation of thermophilic bacterium PS-3 with the Bacillus group (specifically, with $B$. stearothermophilus), which represents the first classification of this bacterium based on molecular terms.

Concerning the high- $\mathrm{G}+\mathrm{C}$ content subgroup of firmicutes, a duplication that specifically involves the groEL gene seems to have occurred in the last ancestor of actinomycetes and mycobacteria (19). Interestingly enough, a clear separation between the high- $\mathrm{G}+\mathrm{C}$ content species of firmicutes in which groEL genes are linked to groES in an operon (labeled [operon] in Fig. 1) and those in which the genes are separated from groES (labeled [gene]) was observed. Moreover, the former genes encode GroEL proteins with unusually high His residue contents at their $C$ termini $(25,34,49)$, a deviation from the classical Gly/Met-rich region found in these proteins (including those encoded by groEL [gene] in these bacteria $[10])$. The significance of this particular idiosyncrasy $(25,34)$, as well as the physiological role of the extra groEL genes (which have evolved differentially [19]), remains obscure.
There exist some controversies concerning the specific relationship between and within the gram-positive bacteria in recent $16 \mathrm{~S}$ rRNA-based trees drawn by different methods $(28$, 31). Our results (Fig. 1) suggest that the high-G+C content and low $-\mathrm{G}+\mathrm{C}$ content subgroups of firmicutes shared a last common ancestor. Although bootstrap analysis does not produce much confidence for this particular result, comparisons of polypeptide sequences indicate the existence of a particular deletion (equivalent to $E$. coli GroEL position 154) which is shared only by the homologous proteins present in firmicutes (49). Therefore, the overall observations support the notion of last common ancestry for the high- $\mathrm{G}+\mathrm{C}$ content and low-G $+\mathrm{C}$ content subgroups of firmicutes, in agreement with maximumlikelihood-derived 16S rRNA trees (31).

Concerning the affiliation of firmicutes with the other eubacterial groups analyzed in this work, our analysis by either the distance (Fig. 1) or the parsimony (data not shown) method indicated that cyanobacteria-chloroplasts and firmicutes are specifically affiliated, a result that was supported by the bootstrap test. Although this particular relationship was also suggested previously by rRNA sequence signatures (53), it is not evident in rRNA-based phylogenetic trees $(28,31,43,53)$.

The overall observations of this work are summarized in Fig. 2. Our results indicate a clear separation between the branches that lead to cyanobacteria-firmicutes on the one hand and spirochetes-chlamydiae-bacteroids-proteobacteria on the other. The uncertainty in defining specific affiliations (branching orders) between certain eubacterial groups is also indicated in Fig. 2 by the shadowed circle.

For a number of reasons, protein sequence comparisons

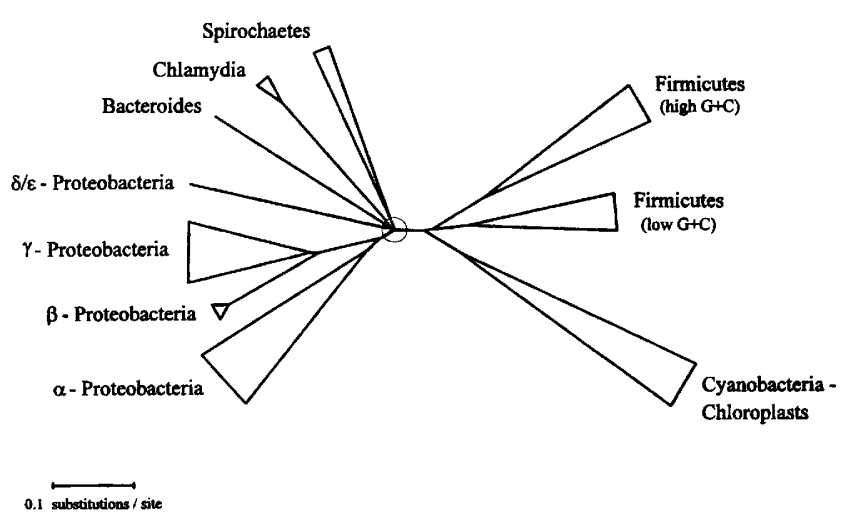

FIG. 2. Evolutionary relationships between eubacterial groups as inferred from GroEL chaperonins. The distinct eubacterial clusters are depicted as triangles in which the base is proportional to the number of GroEL protein sequences and the height represents the average distance (calculated from the data of Fig. 1) separating the terminal nodes from the deepest branching point within the cluster. Branches in which bootstrap support was lower than 50 of 100 replicated trees have been collapsed, and this uncertainty in the branching order is represented by the shaded circle. The evolutionary distance scale is shown at the bottom. 
have not made a large contribution to the field of bacterial systematics (43). In this sense, it appears advantageous to use the identification of GroEL proteins as powerful tools, complementary to rRNA (and other molecules), to define evolutionary relationships among eubacterial species and groups. This emerges as particularly relevant in cases in which affiliations between some eubacterial groups appear controversial, as seems to be the case for $16 \mathrm{~S}$ rRNA trees inferred by different methods $(28,31)$. Since groEL genes have been identified in species of seven of the major groups that compose the eubacterial lineage (i.e., cyanobacteria, firmicutes, spirochetes, chlamydiae, proteobacteria, bacteroids, and Thermus thermophilus [47]) and no sequence-related GroEL proteins have been found in species of Archaea (albeit functional homologs exist [10]), further characterization of groEL genes (especially in the deepest eubacterial branchings [28, 30, 31]) may help to elucidate the evolutionary path of this major lineage of life.

\section{ACKNOWLEDGMENTS}

We are indebted to $J$. Felsenstein for the generous gift of the PHYLIP 3.5 package, to R. Morbidoni for irreplaceable support, and to $H$. Gramajo for patient help with the computer systems. We are also indebted to G. Dasch and E. Weiss for providing information concerning the affiliation of $R$. tsutsugamushi by rRNA analysis.

A.V. is a member of the National Research Council (CONICET, Argentina), and R.F. a fellow of the National University of Rosario. F.S. is a member of the Research Council of the National University of Rosario, and A.A. is a graduate student of the School of Biotechnology, National University of Rosario. This work was supported by grants from CONICET, the Third World Academy of Sciences (Italy), and the International Foundation for Science (Sweden).

\section{REFERENCES}

1. Ahn, T. I., H. K. Leeu, I. H. Kwak, and K. W. Jeon. 1991. Nucleotide sequence and temperature-dependent expression of XgroEL gene isolated from symbiotic bacteria of Amoeba proteus. Endocyt. Cell Res. 8:33-44.

2. Altschul, S. F., W. Gish, W. Miller, E. Myers, and D. J. Lipman. 1990. Basic local alignment research tool. J. Mol. Biol. 215:403-410.

3. Ballard, S. A., R. P. A. M. Segers, N. Bleumink-Pluym, J. Fyfe, S. Faine, and B. Adler. 1993. Molecular analysis of the $h s p$ (groE) operon of Leptospira interrogans serovar copenhageni. Mol. Microbiol. 8:739-751.

4. Brenner, D. J., S. P. O'Connor, H. H. Winkler, and A. G. Steigerwalt. 1993. Proposals to unify the genera Bartonella and Rochalimaea, with descriptions of Bartonella quintana comb. nov., Bartonella vinsonii comb. nov., Bartonella henselae comb. nov., and Bartonella elizabethae comb. nov., and to remove the family Bartonellaceae from the order Rickettsiales. Int. J. Syst. Bacteriol. 43:777-786.

5. Cavalier-Smith, T. 1992. The number of symbiotic origins of organelles. BioSystems 28:91-106.

6. Dasch, G., and K. Swinson. 1992. The phylogeny of Rickettsia tsutsugamushi as deduced from the sequence of its 16S ribosomal RNA gene, abstr. R-6, p. 289. Abstr. 92nd Gen. Meet. Am. Soc. Microbiol. 1992. American Society for Microbiology, Washington, D.C.

7. Dasch, G. A., W. M. Ching, P. Y. Kim, H. Pham, C. K. Stover, E. V. Oaks, M. E. Dobson, and E. Weiss. 1990. A structural and immunological comparison of rickettsial HSP60 antigens with those of other species. Ann. N.Y. Acad. Sci. 590:352-369.

8. Dayhoff, M. O., R. M. Schwartz, and B. C. Orcutt. 1978. A model of evolutionary change in proteins, p. 345-452. In M. O. Dayhoff (ed.), Atlas of protein sequence and structure, vol. 5, suppl. 3. National Biomedical Research Foundation, Washington, D.C.

9. Felsenstein, J. 1988. Phylogenies from molecular sequences: inference and reliability. Annu. Rev. Genet. 22:521-565.

10. Ferreyra, R. G., F. C. Soncini, and A. M. Viale. 1993. Cloning, characterization, and functional expression in Escherichia coli of chaperonin (groESL) genes from the photosynthetic sulfur bacterium Chromatium vinosum. J. Bacteriol. 175:1514-1523.

11. Fischer, H. M., M. Babst, T. Kaspar, G. Acuña, F. Arigoni, and H. Hennecke. 1993. One member of a groESL-like chaperonin multigene family in Bradyrhizobium japonicum is co-regulated with symbiotic nitrogen fixation genes. EMBO J. 12:2901-2912.

12. Gaydos, C. A., L. Palmer, T. C. Quinn, S. Falkow, and J. J. Eiden. 1993. Phylogenetic relationship of Chlamydia pneumoniae to Chlamydia psittaci and Chlamydia trachomatis as determined by analysis of 16S ribosomal DNA sequences. Int. J. Syst. Bacteriol. 43:610-612.

13. Georgopoulos, C., and W. J. Welch. 1993. Role of the major heat shock proteins as molecular chaperones. Annu. Rev. Cell Biol. 9:601-634.

14. Gor, D., and J. E. Mayfield. 1992. Cloning and nucleotide sequence of the Brucella abortus groE operon. Biochim. Biophys. Acta 130:120-122.

15. Hasegawa, M., and T. Hashimoto. 1993. Ribosomal RNA trees misleading? Nature (London) 361:23.

16. Hemmingsen, S. M., C. Woolford, S. M. van der Vies, K. Tilly, D. T. Dennis, C. P. Georgopoulos, R. W. Hendrix, and R. J. Ellis. 1988. Homologous plant and bacterial proteins chaperone oligomeric protein assembly. Nature (London) 333:330-334.

17. Hindersson, P., J. D. Knudsen, and N. H. Axelsen. 1987. Cloning and expression of Treponema pallidum common antigen ( $\mathrm{Tp}-4)$ in Escherichia coli K-12. J. Gen. Microbiol. 133:587-596.

18. Hoffman, P. S., L. Houston, and C. A. Butler. 1990. Legionella pneumophila htp $A B$ heat shock operon: nucleotide sequence and expression of the 60-kilodalton antigen in L. pneumophila-infected HeLa cells. Infect. Immun. 58:3380-3387.

19. Hughes, A. L. 1993. Contrasting evolutionary rates in the duplicate chaperonin genes of Mycobacterium tuberculosis and $M$. leprae. Mol. Biol. Evol. 10:1343-1359.

20. Jukes, T. H., and V. Bhushan. 1986. Silent nucleotide substitutions and $\mathrm{G}+\mathrm{C}$ content of some mitochondrial and bacterial genes. $\mathrm{J}$. Mol. Evol. 24:39-44.

21. Kikuta, L. C., M. Puolakkainen, C. C. Kuo, and L. A. Campbell. 1991. Isolation and sequence analysis of the Chlamydia pneumoniae GroE operon. Infect. Immun. 59:4665-4669.

22. Lehel, C., D. Los, H. Wada, J. Györgyei, I. Horváth, E. Kovács, N. Murata, and L. Vigh. 1993. A second groEL-like gene, organized in a groESL operon is present in the genome of Synechocystis sp. PCC 6803. J. Biol. Chem. 268:1799-1804.

23. Macchia, G., A. Massone, D. Burroni, A. Covacci, S. Censini, and R. Rappuoli. 1993. The Hsp60 protein of Helicobacter pylori. Structure and immune response in patients with gastroduodenal diseases. Mol. Microbiol. 9:645-652.

24. Maid, U., R. Steinmüller, and K. Zetsche. 1992. Structure and expression of a plastid-encoded groEL homologous heat-shock gene in a thermophilic unicellular red alga. Curr. Genet. 21:521-525.

25. Mazodier, P., G. Guglielmi, J. Davies, and C. J. Thompson. 1991. Characterization of the groEL-like genes in Streptomyces albus. J. Bacteriol. 173:7382-7386.

26. Mehra, V., D. Sweetser, and R. A. Young. 1986. Efficient mapping of protein antigenic determinants. Proc. Natl. Acad. Sci. USA 83:7013-7017.

27. Murray, R. G. E. 1984. The higher taxa, or, a place for everything...? p. 31-34. In N. R. Krieg and J. G. Holt (ed.), Bergey's manual of systematic bacteriology, vol. 1 . The Williams \& Wilkins Co., Baltimore.

28. Neefs, J. M., Y. Van de Peer, P. De Rijk, S. Chapelle, and R. De Wachter. 1993. Compilation of small ribosomal subunit RNA structures. Nucleic Acids Res. 21:3025-3049.

29. Ohta, T., K. Honda, M. Kuroda, K. Saito, and H. Hayashi. 1993. Molecular characterization of the gene operon of heat shock proteins HSP60 and HSP10 in methicillin-resistant Staphylococcus aureus. Biochem. Biophys. Res. Commun. 193:730-737.

30. Olsen, G. J., and C. R. Woese. 1993. Ribosomal RNA: a key to phylogeny. FASEB J. 7:113-123.

31. Olsen, G. J., C. R. Woese, and R. Overbeek. 1994. The winds of evolutionary change: breathing new life into microbiology. $J$. Bacteriol. 176:1-6.

32. Parsons, L. M., A. L. Waring, and M. Shayegani. 1992. Molecular 
analysis of the Haemophilus ducreyi groE heat shock operon. Infect. Immun. 60:4111-4118.

33. Paster, B. J., F. E. Dewhirst, I. Olsen, and G. J. Fraser. 1994. Phylogeny of Bacteroides, Prevotella, and Porphyromonas spp. and related bacteria. J. Bacteriol. 176:725-732.

34. Rinke de Wit, T. F., S. Bekelie, A. Osland, T. L. Miko, P. W. M. Hermans, D. van Soolingen, J. W. Drijfhout, R. Schöningh, A. A. M. Janson, and J. E. R. Thole. 1992. Mycobacteria contain two groEL genes: the second Mycobacterium leprae groEL gene is arranged in an operon with groES. Mol. Microbiol. 6:1995-2007.

35. Rusanganwa, E., and R. S. Gupta. 1993. Cloning and characterization of multiple groEL chaperonin-encoding genes in Rhizobium meliloti. Gene 126:67-75.

36. Saitou, N., and M. Nei. 1987. The neighbor-joining method: a new method for reconstructing phylogenic trees. Mol. Biol. Evol. 4:406-425.

37. Sawada, H., H. Ieki, H. Oyaizu, and S. Matsumoto. 1993. Proposal for rejection of Agrobacterium tumefaciens and revised descriptions for the genus Agrobacterium and for Agrobacterium radiobacter and Agrobacterium rhizogenes. Int. J. Syst. Bacteriol, 43:694-702.

38. Schoen, U., and W. Schumann. 1993. Molecular cloning, sequencing, and transcriptional analysis of the groESL operon from Bacillus stearothermophilus. J. Bacteriol. 175:2465-2469.

39. Segal, G., and E. Z. Ron. 1993. Heat shock transcription of the groESL operon of Agrobacterium tumefaciens may involve a hairpin-loop structure. J. Bacteriol. 175:3083-3088.

40. Shanafelt, M. C., P. Hindersson, C. Soderberg, N. Mensi, C. W. Turk, D. Webb, H. Yssel, and G. Peltz. 1991. T cell and antibody reactivity with the Borrelia burgdorferi $60-\mathrm{kDa}$ heat shock protein in Lyme arthritis. J. Immunol. 146:3985-3992.

41. Shinnick, T. M. 1987. The 65-kilodalton antigen of Mycobacterium tuberculosis. J. Bacteriol. 169:1080-1088.

42. Sipos, A., M. Klocke, and M. Frosch. 1991. Cloning and sequencing of the genes coding for the $10-$ and $60-\mathrm{kDa}$ heat shock proteins from Pseudomonas aeruginosa and mapping of a species-specific epitope. Infect. Immun. 59:3219-3226.

43. Sneath, P. H. A. 1989. Analysis and interpretation of sequence data for bacterial systematics: the view of a numerical taxonomist. Syst. Appl. Microbiol. 12:15-31.

44. Steel, M. A., P. J. Lockhardt, and D. Penny. 1993. Confidence in evolutionary trees from biological sequence data. Nature (London) 364:440-442.
45. Stover, C. K., D. P. Marana, G. A. Dasch, and E. V. Oaks. 1990. Molecular cloning and sequence analysis of the Sta58 major antigen gene of Rickettsia tsutsugamushi: sequence homology and antigenic comparison of Sta58 to the 60-kilodalton family of stress proteins. Infect. Immun. 58:1360-1368.

46. Sumner, J. W., K. G. Sims, D. C. Jones, and B. E. Anderson. 1993. Ehrlichia chaffeensis expresses an immunoreactive protein homologous to the Escherichia coli GroEL protein. Infect. Immun. 61:3536-3539.

47. Taguchi, H., J. Konishi, N. Ishii, and M. Yoshida. 1991. A chaperonin from a thermophilic bacterium, Thermus thermophilus, that controls refoldings of several thermophilic enzymes. J. Biol. Chem. 266:22411-22418.

48. Unterman, B. M., P. Baumann, and D. L. McLean. 1989. Pea aphid symbiont relationships established by analysis of $16 \mathrm{~S} \mathrm{rR}$ NAs. J. Bacteriol. 171:2970-2974.

49. Viale, A. M., and A. K. Arakaki. Unpublished observations.

50. Viale, A. M., and A. K. Arakaki. 1994. The chaperone connection to the origins of the eukaryotic organelles. FEBS Lett. 341:146151.

51. Weisburg, W. G., M. E. Dobson, J. E. Samuel, G. A. Dasch, L. P. Mallavia, O. Baca, L. Mandelco, J. E. Sechrest, E. Weiss, and C. R. Woese. 1989. Phylogenetic diversity of the rickettsiae. J. Bacteriol. 171:4202-4206.

52. Willems, A., and M. D. Collins. 1993. Phylogenetic analysis of rhizobia and agrobacteria based on 16S rRNA gene sequences. Int. J. Syst. Bacteriol. 43:305-313.

53. Woese, C. R. 1987. Bacterial evolution. Microbiol. Rev. 51:221271

54. Wong, F. Y. K., E. Stackebrandt, J. K. Ladha, D. E. Fleischman, R. A. Date, and J. A. Fuerst. 1994. Phylogenetic analysis of Bradyrhizobium japonicum and photosynthetic stem-nodulating bacteria from Aeschynomene species grown in separated geographical regions. Appl. Environ. Microbiol. 60:940-946.

55. Zabaleta, E., A. Oropeza, B. Jimenez, G. Salerno, M. Crespi, and L. Herrera-Estrella. 1992. Isolation and characterization of genes encoding chaperonin $60 \mathrm{~b}$ from Arabidopsis thaliana. Gene 111: 175-181.

56. Zavarzin, G. A., E. Stackebrandt, and R. G. E. Murray. 1991. A correlation of phylogenetic diversity in the Proteobacteria with the influence of ecological forces. Can. J. Microbiol. 37:1-6. 